Please quote as: Ernst, S.-J.; Janson, A.; Söllner, M. \& Leimeister, J. M. (2015): When in Rome, do as the Romans do - Overcoming Culture Conflicts in Mobile Learning. In: International Conference on Information Systems (ICIS), Fort Worth, Texas, USA. 


\title{
When in Rome, do as the Romans do - Overcoming Culture Conflicts in Mobile Learning
}

Research-in-Progress

Sissy-Josefina Ernst

Andreas Janson

\author{
Kassel University \\ Information Systems
}

Pfannkuchstr. 1, 34121 Kassel, Germany

[sissy.ernst, andreas.janson]@uni-kassel.de

Matthias Söllner

Jan Marco Leimeister

\author{
Kassel University/University of St. Gallen \\ Information Systems/Institute of Information Management \\ Pfannkuchstr.1, 34121 Kassel, Germany/Unterer Graben 21, 9000 St.Gallen, \\ Switzerland \\ [soellner, leimeister]@uni-kassel.de/[matthias.soellner, \\ janmarco.leimeister]@unisg.ch
}

\begin{abstract}
Mobile learning allows for the embedding of learning into daily routines by means of authentic learning scenarios. In this context, IS research emphasizes the importance of considering individual differences such as cultural differences when using IT in learning scenarios. First, culture is a critical variable that strongly influences IT acceptance and use. Second, teaching concepts differ heavily across cultures. With this research-inprogress paper, we propose a theory-driven design approach to overcome culture conflicts for mobile learning applications. We derive requirements from IT-culture conflict theory and practice, which are addressed by design elements and implemented in a mobile learning application that is now being adapted for China. As a practical contribution of our research, we provide systematic guidance to overcome culture conflicts; as a theoretical contribution, we enrich culture theory by considering and resolving conflicts for mobile learning applications.
\end{abstract}

Keywords: Design science research, mobile learning application, culture conflict 


\section{Introduction}

The use of mobile devices for various purposes is proliferating around the world - an on-going trend that also affects training and education (Docebo 2014). The worldwide market for mobile learning products and services expects a growth rate of some 18\% (Docebo 2014), thus demonstrating great potential for mobile learning services and global distribution, with Asia as one of the strongest drivers of this development (Docebo 2014). China, amongst others, is one of the major addressees of exported educational services, which are often designed by companies from England, USA or Australia (iMOVE 2013). "Today's user interfaces are usually designed in a "one size fits all" approach, disregarding the fact that design preferences differ between cultures" (Reinecke and Bernstein 2013, p. 449). Apart from the user interface, the underlying learning concept and the overall learning scenario are designed for a specific target group and then rolled out globally as well, an approach that may imply some major weaknesses. Against the backdrop of the global use of unadjusted training concepts, research and practice have shown that information technology (IT) use habits vary in different cultures and should be taken into consideration when transferring training concepts (Fischer and Kopp 2007; Sharples 2006; Hofstede 1986). With the application design in mind, former research emphasizes the relevance to consider the user group and their cultural background during the design process of such applications (Fischer and Kopp 2007; Marcus and Gould 2012; Mushtaha and Troyer 2007; Swierczek and Bechter 2010). Therefore, it is important to understand the preferences of the target culture (Habib et al. 2014; Mansar et al. 2012) when designing a mobile learning application in order to meet the needs of the learner.

Nevertheless, taking efficiency aspects into account, it is not possible to restart the development of each IT artifact that lacks the culture factor. It is rather a question of which adjustments need to be taken into consideration in order not to infringe upon norms and values of other cultures. For our design for mobile learning applications, we draw on theory of IT-culture conflict, which suggests that the role of culture within IT use goes mostly unnoticed, unless a conflict occurs (Leidner and Kayworth 2006). This paper considers mobile learning as an integral whole, meaning that the application design, learning concept and scenario are examined from a cultural perspective.

The goal of our research is to present a theory-driven design approach in order to provide a set of design elements to overcome culture conflicts in mobile learning for vocational trainees in China. Taking cultural specifics for an existing application into account and implementing a culture-sensitive design, we seek to improve acceptance and learning outcomes. To achieve our research goal, we follow the design science approach (Hevner et al. 2004; Peffers et al. 2007), particularly the design science research approach of Peffers et al. (2007) (see Figure 1). Hence, our completed research provides a nascent theory of design and action as an improvement for known problems (Gregor 2006; Gregor and Hevner 2013). This research-inprogress paper presents details on the first three phases advocated by Peffers et al. (2007).

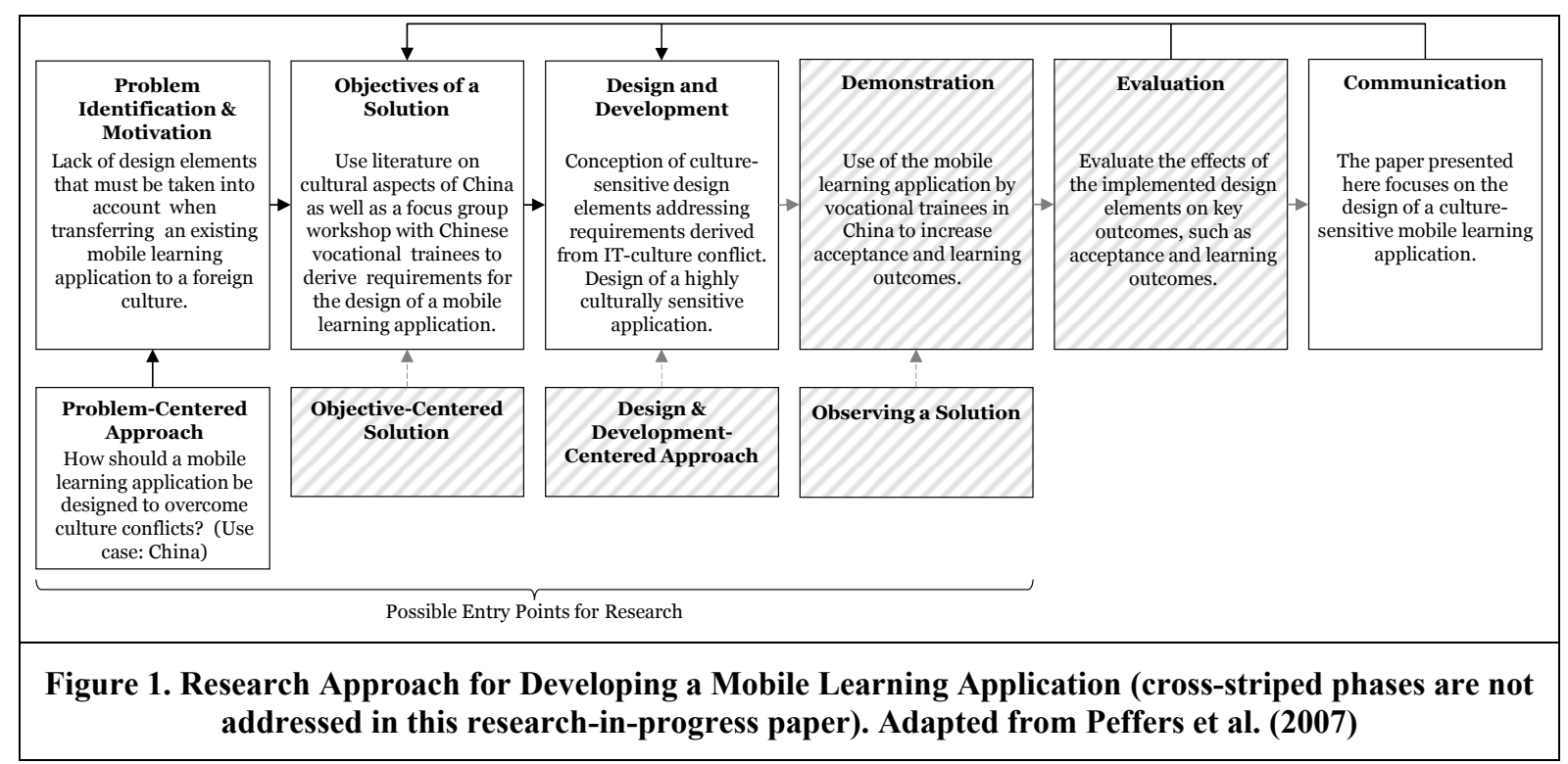


The introduction has addressed the problem of identification and motivation of the design science approach. The remainder of the paper is organized as follows. The next section focuses on the theoretical background of mobile learning applications and culture in information systems research. We subsequently elaborate on the theory of IT-culture conflict as the theoretical basis for our design rationale, before addressing the following activities of the design science approach: the objectives of a solution phase by identifying requirements derived from IT-culture conflict theory and two focus group workshops conducted in China. The third phase, design and development addresses these requirements by culture-sensitive design elements before implementing them in a mobile learning application with the purpose to positively influence acceptance according to use (Figure 1 - cross-striped phases, not addressed in this paper). The paper closes with the planned evaluation, expected contribution and outlook regarding the expected results of our free simulation experiment in China.

\section{Theoretical Background}

Mobile learning is derived from e-learning (De Witt 2013) and is an innovative way of learning based on technical feasibility using ubiquitous media (Kukulska-Hulme and Traxler 2005; Seipold 2013). We define mobile learning as "learners engaged in educational activities, using technology as a mediating tool for learning via mobile devices accessing data and communicating with others through wireless technology" (Wu et al. 2012, p. 818). Flexibility and mobility allow the learner to choose a place and time for learning activities, enabling real-time interaction with learning materials, lecturers and peers (De Witt 2013). Especially when actually applying already acquired factual knowledge, e.g., when setting up a computer or car, mobile learning leads to improved outcomes for learners in terms of training success compared to traditional learning scenarios, as it allows for the provision of immediate and direct feedback (Wu et al. 2012; Zamfiroiu and Sbora 2014). However, research has suggested that users and their cultural differences critically influence the use and learning process in mobile learning (Gupta et al. 2010; Fischer and Kopp 2007; Sharples 2006; Swierczek and Bechter 2010; Lee et al. 2010).

Information systems (IS) research is influenced by approaches based on the considerations of anthropologist Hofstede (1980) to explain cultural differences on a national level, referring to value dimensions when transferring IT-supported learning arrangements to other countries (Anakwe et al. 1999; Liu et al. 2010a; Mushtaha and Troyer 2007; Swierczek and Bechter 2010). In this regard, most studies focus on the process of IS design (Kummer et al. 2012), training concepts (Fischer and Kopp 2007; Gupta et al. 2010) or interface design (Aykin 2007; Reinecke and Bernstein 2013; Marcus and Gould 2012; Mushtaha and Troyer 2007). However, in the case of transferring mobile learning to different cultures, all aspects are of equal importance in terms of the educational and technical design of such an application.

Culture can be seen from a variety of perspectives. One popular way to explain culture considers norms and values that characterize a culture and distinguish it from another (Leidner and Kayworth 2006; Srite and Karahanna 2006; Gallivan and Srite 2005; Hofstede 1980). Another view is to differentiate between approaches based on basic assumptions and approaches using cultural artifacts to describe cultural differences (Schein 1984). In IS research, the value-based approach has become prevalent, since values are more comprehensive than, for example, invisible basic assumptions or indecipherable artifacts (Schein 1984). Cultural research is not only connected to different definitions of culture but also to different layers of applicability. In this context, the onion model of Karahanna et al. (2005) is often used as reference. The authors have proposed a model of interrelated levels of culture consisting of a supranational, national, professional, organizational and group level. An individual's culture as core of the model is the product of all surrounding levels (Karahanna et al. 2005).

IS research has predominantly concentrated on national and organizational culture as the two main layers of reference (Leidner and Kayworth 2006). National culture is used to distinguish attitudes and behavioral differences between people from different countries. In general and also in IS research in specific, the contributions from anthropologist Hofstede (1986) are often used to explain cultural differences on a national level, referring to value dimensions. Similarly, other researchers have established value-based approaches to explain cultural differences on a national level (Hall and Hall 1990; Trompenaars and Hampden-Turner 1998). In contrast, the organizational culture is used to refer to beliefs and attitudes within organizational boundaries (Karahanna et al. 2005; Schein 1990), which has 
also become popular in IS research (Long and Fahey 2000; Hult et al. 2002). However, both approaches are susceptible to outside influences.

The link between national culture and its geographical borders is gradually disintegrating with expanding globalization (Bird and Stevens 2003). Especially in emerging economies such as China, Brazil or India, cultural development is subjected to a permanent change and proposes a variety of value patterns (Martinsons and Ma 2009). Particularly in large countries such as China, society does not constitute a monolithic entity (Li 1996; Cheung and Chow 1999). Both national and organizational culture are influenced by a variety of factors and neither represents an unchangeable value. Corporate changes such as a merger can affect the organizational culture, which may also be influenced by its management (Kavanagh and Ashkanasy 2006) or even by an integrated information system (Clemmons 2007).

Summing up, culture is shaped by several aspects and should be examined from various perspectives. By grounding our research in theory of IT-culture conflict (Leidner and Kayworth 2006), this paper concentrates on culture not only from the viewpoint of a national perspective, but also from the organizational and subunit (or group) level. With IT-culture conflict theory, we are able to consider culture conflicts with IT in a comprehensive way, based on the assumption that cultural aspects only become visible if a conflict occurs, respectively, individuals are not aware of their culture until they confront a counterculture. The conflicts can be differentiated into three types: vision, system, and contribution conflict. They emerge from IT values, group member values and values embedded in a specific IT (see Figure 2).

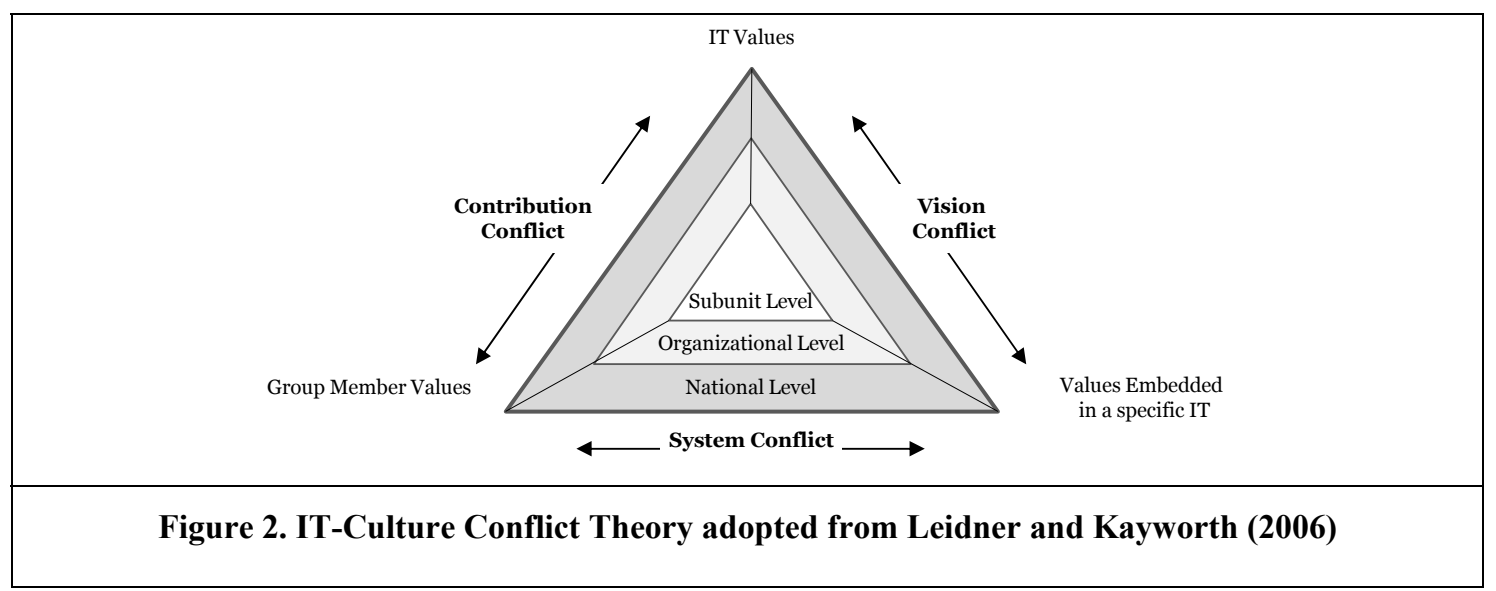

First, the system conflict describes the conflict that emerges from values embedded in a specific IT artifact, which, in turn, contradicts the values held by the group members using the IT artifact. An example would be the transformation of an ERP system intended to increase autonomy among operational levels of a company located in a low power distance country to an affiliated company settled in a high power distance country. As Leidner and Kayworth (2006) point out, the previously described conflict is the most prevalent in research and practice. Second, the contribution conflict explains the contradiction between group member values and the values the group associates with IT in general. To give an example, the contribution conflict can occur when a relationship-oriented group uses IT, even though the group views IT as a tool to promote isolation among people. Third, the vision conflict is a conflict that emerges from a group's IT values associated with IT in general and values embedded within a specific IT artifact. An example would be to provide software designed to increase efficiency, i.e., process management software to a group experiencing IT as a time-consuming burden (cf. Leidner and Kayworth 2006).

\section{Theory-driven Design to Overcome Culture Conflicts}

To derive our design for mobile learning applications, we draw on theory of IT-culture conflict (Leidner and Kayworth 2006). In consequence, theory-driven design (Briggs 2006; Gehlert et al. 2009) should consider potential culture conflicts that may hinder the use of a specific IT artifact and accordingly address these conflicts in the design process. In particular, we focus on culture conflicts that may occur 
when providing mobile learning applications worldwide without any adaptation to cultural preferences. As shown below, occurring culture conflicts negatively influence the use of such applications directly (Koch et al. 2013; Leidner and Kayworth 2006), thus resulting in poorer learning outcomes. As Leidner and Kayworth (2006) state, groups are more likely to use a technology when their own values fit the values embedded within a technology. As a consequence, user are either reluctant to use or will use a technology in unexpected ways (Koch et al. 2013; Chau et al. 2002). Hence, values influence the adoption and use of a technology and thus the expected outcomes (Leidner and Kayworth 2006). Therefore, culture conflicts have an indirect impact on the effect of use on learning outcomes. Even in terms of limited conflict scopes, changes in user behavior or the kind-of-use can negatively affect the acquisition of knowledge (Liu et al. 2010b; Chen et al. 1999). Figure 3 illustrates our theory-driven design approach in line with the framework of Gupta and Bostrom (2009).

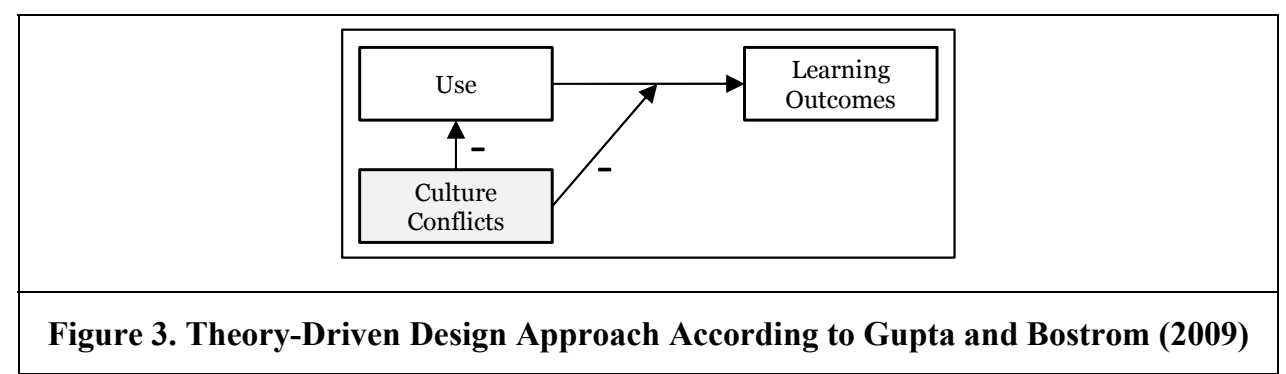

The framework of the use case presented below is the vocational training of motor mechanics in Chinese vocational schools. The mobile learning application that serves as a basis offers two different types of tasks: the mobile learning application facilitates declarative knowledge by compromising fundamentals, but it facilitates procedural knowledge by displaying damage descriptions and calling on the user to develop a strategy to detect the cause of damage. Starting from the idea of enhancing the training of motor mechanics in China by applying this mobile learning concept with its origin in Germany, we consider certain adjustments to avoid culture conflicts.

Our approach includes three steps for avoiding culture conflicts. As a first step, we derive general requirements concerning mobile learning in China from theory by considering the described IT-culture conflict types. Here, we consider mobile learning as an overall concept, which means that the design of the application, its underlying learning concept, as well as the learning scenario are examined from a theoretical perspective. In the second step, we derive requirements from practice, also taking into account the conflict types. For this purpose, we conducted two focus group workshops in Chinese vocational schools. In the final step, we addressed all identified culture conflicts and their assigned requirements with theory-driven design elements in the design and development phase.

The objectives of the initiated workshops were the identification of culture conflicts in the mobile learning training with its origin in Germany. For this purpose, we provided the original mobile learning application translated into Chinese. We developed the mobile learning application within an ongoing research project by experts in the fields of teaching and training (Janson et al. 2014), thus ensuring that the application which served as a basis constituted a high standard of quality in mobile learning. As stated earlier, culture should be examined from various perspectives. The theoretical derivation of requirements considers culture conflicts on a national level. To acquire a more precise cultural fit, we addressed conflicts regarding the organizational and subunit level by conducting the two focus group workshops with our target culture, namely Chinese vocational students. The theoretical and the practical derivation of requirements represent the two parts of the objectives of a solution phase, as stated in Figure 1.

\section{Requirements from IT-Culture Conflict Theory}

In this section, we address the first part of the objectives of the solution phase of the design science approach of Peffers et al. (2007) by deriving requirements from IT-culture conflict theory. The theory of IT-culture conflict (Leidner and Kayworth 2006) considers three possible types of IT-culture conflicts. The theoretical derivation of requirements for our mobile learning application considers culture on a national level. We seek to address each conflict from theory for our case by means of a literature review. 
Summing up, we can identify five requirements from theory ( $\mathrm{T}_{1}-\mathrm{T}_{5}$ in Table 1 ) to ensure that no conflict arises when deploying mobile learning in Chinese schools.

Table 1. Requirements from Theory of IT-Culture Conflict

\begin{tabular}{|l|l|}
\hline Culture Conflict & Derived Requirements from Theory (T) \\
\hline System Conflict & $\begin{array}{l}\text { T1) The mobile learning application should offer a lecturer-centered learning approach. } \\
\text { T2) The mobile learning application should ensure the learners' anonymity to the extent necessary to } \\
\text { prevent a loss of face, e.g., when making an error. } \\
\text { T3) The mobile learning application should consider user interface elements that are preferred by } \\
\text { Chinese learners. }\end{array}$ \\
\hline Contribution Conflict & T4) The mobile learning application should be effectively embedded into the current learning process. \\
\hline Vision Conflict & $\begin{array}{l}\text { T5) The mobile learning application should consider elements that reflect the Chinese learners' } \\
\text { expectations and views of mobile applications in general. }\end{array}$ \\
\hline
\end{tabular}

The first requirement $(\mathbf{T} \mathbf{1})$ deals with system conflicts within different learning concepts that are embedded in the IT artifact. Learning concepts in China still consider a lecturer-centered approach with little room for self-regulated learning (Gao 1998; Olaussen and Brăten 1999). In consequence, the design of the mobile learning application has to consider this approach by providing additional guidance in the learning process (Gupta and Bostrom 2009). The second system conflict requirement (T2) deals with the issue of a loss of face in the learning process. In a Chinese context, a fully transparent training process would result in a system conflict because a loss of face (Redding and Ng 1983) would hinder the use and effectiveness of the mobile learning application. Design preferences are a typical consideration of cultural differences in IS research (Reinecke and Bernstein 2013). We also recognize this need and therefore require our design to consider such preferences (T3). Interaction in Chinese learning scenarios is often limited to a one-sided interaction with a lecturer and classic learning materials such as books (Fischer and Kopp 2007; Gao 1998). Hence, mobile learning applications should be embedded into this learning process by respecting existing learning methods, structures and processes (T4). Cultural differences have a significant impact on the adoption of smartphones (Arpaci et al. 2013). Considering our case, mobile applications in China are mainly used for gaming purposes or for chatting and cultivating contacts (CNNIC 2012). Hence, conflict arises when introducing mobile applications that do not consider habitual motives of usage but are instead designed for learning purposes. Thus, the last requirement (T5) deals with the consideration of the vision conflict in order to enable a fit of the specific IT artifact and the general values the user group assigns to the IT artifact.

\section{Requirements from a Focus Group Workshop}

In addition to the theoretical derivation of requirements for our mobile learning application, we seek to address the second part of the objectives of a solution phase of the design science cycle by deriving requirements from two focus group workshops. As has already been pointed out, culture is a complex construct that should not be classified merely by its national borders, since it is shaped by various influences. We have therefore initiated two focus group workshops in Chinese vocational schools. Both schools are located in industry-oriented provinces in the east of China. Thus, we address culture on an organizational and subunit level by deriving requirements from our target group. The 22, respectively, 19 predominantly male participants were students in their first or third year of motor mechanics training with an average age of 18.3 and 19.0. The utilization of focus groups is considered an effective method to generate various ideas (Greenbaum 1998). Structuring the focus group workshop, we followed the collaboration process design approach of Kolfschoten and Vreede (2009). The overall objectives of the initiated workshops were the identification of culture conflicts in the mobile learning concept with its origin in Germany. Providing the original mobile learning application translated into Chinese, the students had to complete different tasks, e.g., studying fundamentals, answering multiple choice questions and finding solutions to complex problems. Afterwards, the students had some time to discover functions and features of the application. Next, we guided the students through different collaborative process steps (Leimeister 2014).

The first step of the conducted workshop constituted brainstorming in order to collect a variety of aspects the students negatively noticed concerning the application itself and its underlying learning concept. After noting their change requests on cards, the students were asked to discuss their wishes for improvement in 
groups of five. The moderated discussion aimed at ensuring that every participant had a clear conception of the written change requests. After summarizing similar change requests into clusters, the remaining clusters were rated by sticking points on cards with the most significant change requests. Each student received three sticking points to indicate the change requests reflecting their interests. Afterwards, the aspects with the highest scores in each group were reported to the class. Summing up, the workshops resulted in 11 varying requirements. The requirements $\left(\mathrm{P}_{1}-\mathrm{P} 11\right)$ are listed and assigned to their corresponding type of conflict in Table 2.

\begin{tabular}{|l|l|}
\hline \multicolumn{2}{|c|}{ Table 2. Requirements from Focus Group Workshop } \\
\hline Culture Conflict & Requirements of the Practical Application (P) \\
\hline & $\begin{array}{l}\text { P1) The mobile learning application should not provide the scores to the teacher. } \\
\text { P2) The mobile learning application should animate pictures and text to improve the design. } \\
\text { P3) The mobile learning application should integrate instructions that provide guidance for tasks. } \\
\text { P4) The mobile learning application should integrate hints on how to perform a task and integrate } \\
\text { feedback loops after each task. } \\
\text { P5) The mobile learning application should integrate multimedia content and pictures. } \\
\text { P6) The mobile learning application should integrate bright colors. }\end{array}$ \\
\hline Contribution Conflict & P7) The mobile learning application should integrate content based on current learning materials. \\
\hline Vision Conflict & $\begin{array}{l}\text { P8) The mobile learning application should integrate animated games. } \\
\text { P9) The mobile learning application should integrate a ranking by points to determine a winner. } \\
\text { P10) The mobile learning application should integrate a countdown timer for each task. } \\
\text { P11) The mobile learning application should integrate a function that supports peer interaction. }\end{array}$ \\
\hline
\end{tabular}

All listed requirements address particular aspects of the mobile learning application and provide detailed insights into student expectations towards such an application. We conducted a survey on the workshop participants based on the general workshop assessment (Briggs et al. 2014) to measure their satisfaction with the collaboration process. The survey tested the participants' perceived satisfaction with the workshop process and outcome (Briggs et al. 2014). All items were measured on a 7-point Likert scale. In brief, the results of a one-sample t-test with 4 as the reference value show that average process satisfaction was rated $6.3(\mathrm{p}<0.001)$ in the first, and $6.0(\mathrm{p}<0.001)$ in the second, workshop. Satisfaction with the workshop outcome was rated $5.7(\mathrm{p}<0.001)$ and $5.8(\mathrm{p}<0.001)$. The results reflect a high degree of satisfaction with the workshops and the results.

\section{Design Elements to Overcome Culture Conflicts}

Addressing the design and development phase of the design science approach, the following section deduces design elements concerning the identified requirements derived from IT-culture conflict theory. Table 3 presents the composition of requirements and the corresponding culture-sensitive design elements.

\begin{tabular}{|l|l|l|l|}
\hline \multicolumn{5}{|c|}{ Table 3. Design Elements for Mobile Learning in China } \\
\hline $\begin{array}{l}\text { Culture } \\
\text { Conflict }\end{array}$ & Design Element & Description & $\begin{array}{l}\text { Addressed } \\
\text { Req. }\end{array}$ \\
\hline $\begin{array}{l}\text { System } \\
\text { Conflict }\end{array}$ & Integration of an avatar & $\begin{array}{l}\text { Integration of an avatar to give the students guidance concerning the use } \\
\text { of the learning application. }\end{array}$ & T1, P3, P4 \\
\cline { 2 - 5 } & Anonymous user data & $\begin{array}{l}\text { The students have the possibility of using the mobile learning } \\
\text { application and its functions by themselves, anonymously. }\end{array}$ & T2, P1 \\
\cline { 2 - 5 } & Culture-specific UI & $\begin{array}{l}\text { Integration of culture-specific user interface elements according to the } \\
\text { preferences of the target group culture. }\end{array}$ & T3, P2, P5, P6 \\
\hline $\begin{array}{l}\text { Contribution } \\
\text { Conflict }\end{array}$ & $\begin{array}{l}\text { Educational content } \\
\text { adapted to curriculum }\end{array}$ & Integration of educational content adapted to the curriculum. & T4, P7 \\
\hline Vision Conflict & Concept of gamification & $\begin{array}{l}\text { Integration of gamification elements as an extrinsic incentive to motivate } \\
\text { the students to use the mobile learning application continuously. }\end{array}$ & T5, P8, P9, P10 \\
\cline { 2 - 5 } & Peer interaction & $\begin{array}{l}\text { Integration of a chat function to support peer interaction amongst the } \\
\text { users. }\end{array}$ & T5, P11 \\
\hline
\end{tabular}


Learners in Asian countries typically do not learn in a self-regulated way (Olaussen and Bråten 1999; Purdie and Hattie 1996). The teacher guides the students through different teaching cases as a parental director (Gao 1998). Providing a learning application to students without administering guidance or instruction by a teacher, the students might feel lost or unmotivated to use the application. For this purpose, we integrated an avatar to give the students guidance concerning the use of the learning application. The avatar appears whenever a teacher in a real learning scenario would talk, help or provide guidance to the class ( $\left.\mathrm{T}_{1}, \mathrm{P}_{3}, \mathrm{P}_{4}\right)$.

Redding and Ng (1983) point out that people from Asia tend to lose face when feeling ashamed (Redding and $\mathrm{Ng}$ 1983). Chinese students generally feel immense pressure to obtain high academic achievement (Lin and Chen 1995). Examining mobile communication technology in Chinese schools, Rau et al. (2008) call attention to the fact that media demanding self-exposure might increase the pressure to succeed. The learning application does not provide student scores or failures to any principal. We thereby assume that by reducing the pressure to succeed we prevent students from losing face when they fail (T2, P1).

Particular attention must be paid to the user group and their cultural background during the user interface design process (Marcus and Gould 2012). Recipients of the learning application are vocational trainees in the field of motor mechanics in China. Therefore, we implement design elements based on existing user interface research addressing different cultures (Reinecke and Bernstein 2011), drawing on a value-based approach on a national level (Hofstede 1980). In order to ensure that these insights also work on an organizational and subunit level, we crosschecked the results with our focus groups. Since the results from theory and practice are consistent, we consequently used Reinecke and Bernstein's insights to address the user interface preferences of our target culture ( $\left.\mathrm{T}_{3}, \mathrm{P}_{2}, \mathrm{P} 5, \mathrm{P} 6\right)$.

In contrast to practical skills, textbooks as theoretical knowledge are attributed to be very important (Gao 1998) in Chinese learning environments. Here, the teacher plays an outstanding role, thus extending the typical task of merely teaching knowledge (Yu 1959; Zhen 1973). Hence, a learning application can never entirely replace a teacher or a book. As a result, we develop a mobile learning application that promotes self-regulated learning and practical knowledge. Additionally, the application includes educational content adapted to the curriculum in order to emphasize its importance for the school career $\left(\mathrm{T}_{4}, \mathrm{P}_{7}\right)$.

On average, $84.8 \%$ of all Chinese go online via smartphone for contacting friends and $62 \%$ for relaxation and entertainment (CNNIC 2012). Since Chinese students will most likely not use a mobile learning application without extrinsic incentives, we apply the concept of gamification, i.e., the use of game elements in a non-game context (Hanus and Fox 2015; Thiebes et al. 2014), which has great potential for motivating IS users (Thiebes et al. 2014). Furthermore, we integrate a function that supports peer interaction, thus giving students the opportunity to help each other in finding effective solutions for the implemented tasks. We are currently developing a connection to WeChat, which is a popular messaging application in China. As a result, we hope to gain a better fit to the usage habits of Chinese students and hence to overcome the vision conflict (T5, P8, P9, P10, P11).

\section{Experimental Design for the Planned Evaluation}

In order to evaluate whether the derived design elements lead to higher acceptance and learning outcomes, as stated in our research model, we are currently developing a mobile learning application that takes the design consideration into account. Figure 4 displays screenshots of the developed prototypes.
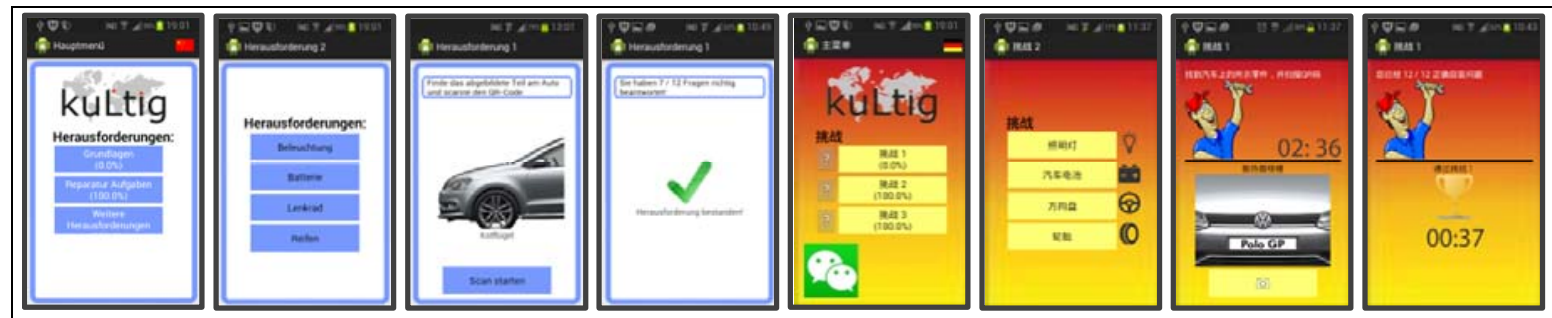

Figure 4. On the Left: Basis Application; on the Right: Culture-Sensitive Mobile Learning Application intended for use in China. 
For the evaluation, we will conduct an experiment in China. The evaluation is planned within a vocational teaching scenario. For this purpose, we plan to return to the Chinese vocational schools for motor mechanics we visited when conducting the two focus group workshops, thus, keeping the target group consistent. We plan to divide the students into two groups; one group will use the adapted application (shown in Figure 4 on the right), while the second group will use the unmodified mobile learning application (shown in Figure 4 on the left). Participants are drawn from the course and randomly assigned to one of the groups. In addition, a pre-test with a subset of questions from a cognitive knowledge test is carried out to ensure that all participants are novices regarding the learning content that the mobile learning application imparts. Additionally, we measure control variables in the pre-test (Rammstedt and John 2007; Pintrich and De Groot 1990). We will ask the students to complete predefined tasks involving different learning activities supported by the application. Afterwards, the students will be asked to fill out a post-test in order to capture our dependent variables.

In accordance with the theory-driven design approach (shown in Figure 3), we will evaluate IT acceptance (Davis 1989), which can be negatively influenced by occurring culture conflicts (Koch et al. 2013; Leidner and Kayworth 2006). We use a 7-point Likert scale to assess the indicators. Furthermore, occurring culture conflicts have an indirect impact on learning outcomes. As shown before, values influence the adoption and use of information systems and thus the expected outcomes (Leidner and Kayworth 2006). To measure learning outcomes, we draw on the approach of Gupta and Bostrom (2013) and measure cognitive knowledge acquisition, meta-cognitive, as well as affective outcomes. Since our application facilitates declarative and procedural knowledge, we will take both knowledge types into consideration of our planned knowledge test. To evaluate the impact of the design elements on the dependent variables, we use a t-test to evaluate whether there is a significant improvement in IT acceptance and learning success.

\section{Expected Contribution and Outlook}

The expected contribution of our completed research is twofold. We provide a theory of design and action according to Gregor (2006) and hence a new solution to the problem of culture conflict in IT deployment (Gregor and Hevner 2013). Thus, we contribute to theory by systematically considering theory-driven requirements to overcome culture conflicts in the design of a mobile learning application. Hence, we gain further understanding of how we can adapt mobile learning applications to individual needs. By appreciating the role of culture in mobile learning, we enable theory for a deeper and more valid understanding of the nature of mobile learning (Chen et al. 1999). Connected to this stands the practical contribution of our research, enabling practitioners to design mobile learning applications in a culturally sensitive way. By providing guidance with IT-culture conflict theory, acceptance and learning outcomes are able to be improved across different cultures. With this research-in-progress paper the preliminary design of our mobile learning application to overcome culture conflicts in China is completed. We now implement the design in an application that is currently running with the Android operating system. After implementation, we will advance our research to the demonstration and evaluation phase of the design science research approach (according to Peffers et al. (2007) and described in section 1) to publish the results of the completed research.

\section{Acknowledgements}

Our thanks go to all participating students of the Yizheng Technician College and the Hefei Vocational and Technical College, without whose support the study would not have been possible. The research presented in this paper was funded by the German Federal Ministry of Education and Research in the project kuLtig (www.projekt-kuLtig.de), FKZ 01BEXo5A13.

\section{References}

Anakwe, U. P., Kessler, E. H., and Christensen, E. W. 1999. "Distance Learning and Cultural Diversity: Potential Users' Perspective," International Journal of Organizational Analysis (7:3), pp. 224-243.

Arpaci, I., Yardimci, Y. C., and Turetken, O. 2013. "The impact of cultural differences on smartphone adoption by organizations," in 2013 Third International Conference on Innovative Computing Technology (INTECH), London, United Kingdom, pp. 421-423. 
Aykin, N. (ed.) 2007. Usability and Internationalization. Global and Local User Interfaces, Berlin, Heidelberg: Springer Berlin Heidelberg.

Bird, A., and Stevens, M. J. 2003. "Toward an emergent global culture and the effects of globalization on obsolescing national cultures," Journal of International Management (9:4), pp. 395-407.

Briggs, R. O. 2006. "On theory-driven design and deployment of collaboration systems," International Journal of Human-Computer Studies (64:7), pp. 573-582.

Briggs, R. O., Reinig, B. A., and Vreede, G. J. de 2014. "An Empirical Field Study of the Yield Shift Theory of Satisfaction," System Sciences, Proceedings of the 47th Hawaii International Conference on System Science, pp. 492-499.

Chau, P. Y. K., Cole, M., Massey, A. P., Montoya-Weiss, M., and O'Keefe, R. M. 2002. "Cultural differences in the online behavior of consumers," Communications of the ACM (45:10), pp. 138-143.

Chen, A.-Y., Mashhadi, A., Ang, D., and Harkrider, N. 1999. "Cultural Issues in the Design of TechnologyEnhanced Learning Systems," British Journal of Educational Technology (30:3), pp. 217-230.

Cheung, G. W., and Chow, I. H.-S. 1999. "Subcultures in Greater China: A Comparison of Managerial Values in the People's Republic of China, Hong Kong, and Taiwan," Asia Pacific Journal of Management (16:3), pp. 369-387.

Clemmons, S. 2007. "Cross Cultural Implications of the Technology Artifact," AMCIS 2007 Proceedings.

CNNIC 2012. "Reasons for going online via cell phone in China 2012," Mobile internet in China - Statista Dossier 2013, p. 33.

Davis, F. D. 1989. "Perceived Usefulness, Perceived Ease of Use, and User Acceptance of Information Technology," MIS Quarterly (13:3), p. 319.

De Witt, C. 2013. "Vom E-Learning zum Mobile Learning - wie Smartphones und Tablet PCs Lernen und Arbeit verbinden," in Mobile Learning: Potenziale, Einsatzszenarien und Perspektiven des Lernens mit mobilen Endgeräten, C. De Witt, and A. Sieber (eds.): Springer Verlag, pp. 12-26.

Docebo 2014. "Learning on the go: Tips and trends in m-learning - a report,"

Fischer, B., and Kopp, B. 2007. "Evaluation of a Western training concept for further education in China," Interculture Journal (6:4), pp. 57-76.

Gallivan, M., and Srite, M. 2005. "Information technology and culture: Identifying fragmentary and holistic perspectives of culture," Information and Organization (15:4), pp. 295-338.

Gao, L. 1998. "Cultural context of school science teaching and learning in the People's Republic of China," Science Education (82:1), pp. 1-13.

Gehlert, A., Schermann, M., Pohl, K., and Krcmar, H. 2009. "Towards a Research Method for Theorydriven Design Research," Wirtschaftinformatik Proceedings 2009.

Greenbaum, T. L. 1998. The handbook for focus group research, Thousand Oaks (CA), London, New Delhi: SAGE.

Gregor, S. 2006. "The nature of theory in information systems," (30:3), pp. 611-642.

Gregor, S., and Hevner, A. R. 2013. "Positioning and Presenting Design Science Research for Maximum Impact," MIS Quarterly (37:2), pp. 337-A6.

Gupta, S., and Bostrom, R. 2009. "Technology-Mediated Learning: A Comprehensive Theoretical Model," Journal of the Association for Information Systems (10:9), pp. 686-714.

Gupta, S., and Bostrom, R. 2013. "An Investigation of the Appropriation of Technology-Mediated Training Methods Incorporating Enactive and Collaborative Learning," Information Systems Research (24:2), pp. 454-469.

Gupta, S., Bostrom, R. P., and Anson, R. 2010. "Do I matter? The impact of individual differences on training process," Proceedings of the 2010 Special Interest Group on Management Information System's 48th annual conference on Computer personnel research, pp. 112-120.

Habib, L., Johannesen, M., and Ogrim, L. 2014. "Experiences and Challenges of International Students in Technology-Rich Learning Environments," Educational Technology \& Society (17:2), pp. 196-206.

Hall, E. T., and Hall, M. R. 1990. Understanding cultural differences, Yarmouth, Maine: Intercultural Press.

Hanus, M. D., and Fox, J. 2015. "Assessing the effects of gamification in the classroom: A longitudinal study on intrinsic motivation, social comparison, satisfaction, effort, and academic performance," Computers \& Education (80), pp. 152-161.

Hevner, A. R., March, S. T., Park, J., and Ram, S. 2004. "Design Science in Information Systems Research," MIS Quarterly (28:1), pp. 75-105.

Hofstede, G. 1980. Culture's consequences: International differences in work-related values: Sage Publications, Inc. 
Hofstede, G. 1986. "Cultural differences in teaching and learning," International Journal of Intercultural Relations (10:3), pp. 301-320.

Hult, G. T. M., Ketchen, D. J., and Nichols, E. L. 2002. "An Examination of Cultural Competitiveness and Order Fulfillment Cycle Time within Supply Chains," Academy of Management Journal (45:3), pp. $577-586$.

iMOVE 2013. Trendbarometer: Exportbranche Aus- und Weiterbildung. https://www.imovegermany.de/cps/rde/xbcr/imove_projekt_de/p_iMOVE_Trendbarometer_2013_sicher.pdf.

Janson, A., Peters, C., and Leimeister, J. M. 2014. "Der Weg zur effizienten Bereitstellung kultursensitiver Dienstleistungen - erste Schritte mittels systematischer Modularisierung," in Dienstleistungsmodellierung 2014, O. Thomas, and M. Nüttgens (eds.), pp. 266-286.

Karahanna, E., Evaristo, J. R., and Srite, M. 2005. "Levels of Culture and Individual Behavior: An Integrative Perspective," Journal of Global Information Management (13:2), pp. 1-20.

Kavanagh, M. H., and Ashkanasy, N. M. 2006. "The Impact of Leadership and Change Management Strategy on Organizational Culture and Individual Acceptance of Change during a Merger," British Journal of Management (17:S1), pp. S81-S103.

Koch, H., Leidner, D. E., and Gonzalez, E. S. 2013. "Digitally enabling social networks: resolving ITculture conflict," Information Systems Journal, pp. 501-523.

Kolfschoten, G. L., and Vreede, G.-J. de 2009. "A Design Approach for Collaboration Processes: A Multimethod Design Science Study in Collaboration Engineering," Journal of Management Information Systems (26:1), pp. 225-256.

Kukulska-Hulme, A., and Traxler, J. 2005. Mobile learning: A handbook for educators and trainers, London: Routledge.

Kummer, T.-F., Leimeister, J. M., and Bick, M. 2012. "On the Importance of National Culture for the Design of Information Systems," Business \& Information Systems Engineering (4:6), pp. 317-330.

Lee, I., Kim, J., Choi, B., and Hong, S.-J. 2010. "Measurement development for cultural characteristics of mobile Internet users at the individual level," Computers in Human Behavior (26:6), pp. 1355-1368.

Leidner, D. E., and Kayworth, T. 2006. "Review: A Review of Culture in Information Systems Research: Toward a Theory of Information Technology Culture Conflict," MIS Quarterly (30:2), pp. 357-399.

Leimeister, J. M. 2014. Collaboration Engineering, Berlin, Heidelberg: Springer Berlin Heidelberg.

Li, C. 1996. "Rediscovering urban subcultures: The contrast between Shanghai and Bejing," The China Journal (36), pp. 139-153.

Lin, J., and Chen, Q. 1995. “Academic Pressure and Impact in Students' Development in China," McGill Journal of Education (30:2), pp. 149-168.

Liu, X., Liu, S., Lee, S.-h., and Magjuka, R. J. 2010a. "Cultural Differences in Online Learning: International Student Perceptions," Educational Technology \& Society (13:3), pp. 177-188.

Liu, Y., Han, S., and Li, H. 2010b. "Understanding the factors driving m-learning adoption: a literature review," Campus-Wide Information Systems (27:4), pp. 210-226.

Long, D. W. de, and Fahey, L. 200o. "Diagnosing cultural barriers to knowledge management," Academy of Management Perspectives (14:4), pp. 113-127.

Mansar, S. L., Jariwala, S., Shahzad, M., Anggraini, A., Behih, N., and AlZeyara, A. 2012. "A Usability Testing Experiment For A Localized Weight Loss Mobile Application," Procedia Technology (5), pp. 839-848.

Marcus, A., and Gould, E. W. 2012. "Globalization, Localization, and Cross-Cultural User-Interface Design," in The human-computer interaction handbook: Fundamentals, evolving technologies, and emerging applications, J. A. Jacko (ed.), Boca Raton, FL: CRC Press, pp. 341-366.

Martinsons, M., and Ma, D. 2009. "Sub-Cultural Differences in Information Ethics across China: Focus On Chinese Management Generation Gaps," Journal of the Association for Information Systems (10:11).

Mushtaha, A., and Troyer, O. 2007. "Cross-Cultural Understanding of Content and Interface in the Context of E-Learning Systems," in Usability and Internationalization. Global and Local User Interfaces, N. Aykin (ed.), Berlin, Heidelberg: Springer Berlin Heidelberg, pp. 164-173.

Olaussen, B. S., and Bråten, I. 1999. "Students' Use of Strategies for Self-regulated Learning: cross-cultural perspectives," Scandinavian Journal of Educational Research (43:4), pp. 409-432.

Peffers, K., Tuunanen, T., Rothenberger, M. A., and Chatterjee, S. 2007. "A design science research methodology for information systems research," Journal of Management Information Systems (24:3), pp. 45-77. 
Pintrich, P. R., and De Groot, E. V. 1990. "Motivational and self-regulated learning components of classroom academic performance," Journal of educational psychology (82:1), p. 33.

Purdie, N., and Hattie, J. 1996. "Cultural Differences in the Use of Strategies for Self-Regulated Learning," American Educational Research Journal (33:4), pp. 845-871.

Rammstedt, B., and John, O. P. 2007. "Measuring personality in one minute or less: A 10-item short version of the Big Five Inventory in English and German," Journal of Research in Personality (41:1), pp. 203-212.

Rau, P.-L. P., Gao, Q., and Wu, L.-M. 2008. "Using mobile communication technology in high school education: Motivation, pressure, and learning performance," Computers \& Education (50:1), pp. 122.

Redding, S. G., and Ng, M. 1983. "The role of" face" in the organizational perceptions of Chinese managers," International Studies of management \& Organisation (13:3), pp. 92-123.

Reinecke, K., and Bernstein, A. 2011. "Improving performance, perceived usability, and aesthetics with culturally adaptive user interfaces," ACM Transactions on Computer-Human Interaction (18:2), pp. 1-29.

Reinecke, K., and Bernstein, A. 2013. "Knowing what a User Likes: A Design Science Approach to Interfaces that Automatically Adapt to Culture,” MIS Quarterly (37:2), pp. 427-453.

Schein, E. H. 1984. "Coming to a New Awareness of Organizational Culture," Sloan Management Review (25:2), pp. 3-16.

Schein, E. H. 1990. "Organizational culture," American psychologist (45:2), pp. 109-119.

Seipold, J. 2013. "Mobiles Lernen - Systematik, Theorien und Praxis eines noch jungen Forschungsfeldes," in Mobile Learning: Potenziale, Einsatzszenarien und Perspektiven des Lernens mit mobilen Endgeräten, C. De Witt, and A. Sieber (eds.): Springer Verlag, pp. 27-54.

Sharples, M. 2006. "Big Issues in Mobile Learning," Report of a workshop by Kaleidoscope Network of Excellence Mobile Learning Initiative.

Srite, M., and Karahanna, E. 2006. “The Role of Espoused National Cultural Values in Technology Acceptance," MIS Quarterly (30:3), pp. 679-704.

Swierczek, F. W., and Bechter, C. 2010. "Cultural Features of e-Learning," in Learning and Instruction in the Digital Age, J. M. Spector, D. Ifenthaler, P. Isaias, Kinshuk, and D. Sampson (eds.), Boston, MA: Springer US, pp. 291-308.

Thiebes, S., Lins, S., and Basten, D. 2014. "Gamifying Information Systems - a Synthesis of Gamification Mechanics and Dynamics," Proceedings of the European Conference on Information Systems.

Trompenaars, F., and Hampden-Turner, C. 1998. Riding the waves of culture, New York, NY, USA: McGraw-Hill.

Wu, W.-H., Jim Wu, Y.-C., Chen, C.-Y., Kao, H.-Y., Lin, C.-H., and Huang, S.-H. 2012. "Review of trends from mobile learning studies: A meta-analysis," Computers \& Education (59:2), pp. 817-827.

$\mathrm{Yu}$, H. 1959. "Shi shuo (on teachers)," in Gu wen guam zhi (A primer of classical Chinese texts), C. Wu, and D. Wu (eds.), Bejing: Zhonghua shuju, pp. 333-335.

Zamfiroiu, A., and Sbora, C. 2014. "Statistical Analysis of the Behavior for Mobile E-learning," Procedia Economics and Finance (10), pp. 237-243.

Zhen, L. 1973. The Way of Being a Teacher in China, Taipei: Chung Hwa Book Co., Ltd. 